\title{
Studying Depression, Anxiety, Distress and Somatisation in a Community Sample of 2,425 Adults in Greece
}

\author{
Maya Louvardi ${ }^{1}$, Panagiotis Pelekasis ${ }^{1}$, Flora Bacopoulou ${ }^{\circledR}$, Dimitrios Vlachakis ${ }^{2,3,4}$, George P. Chrousos ${ }^{1,2}$, \\ Christina Darviri ${ }^{1}$ \\ ${ }^{1}$ Postgraduate Course of Science of Stress and Health Promotion, School of Medicine, National and Kapodistrian University of \\ Athens, Athens, Greece \\ ${ }^{2}$ University Research Institute of Maternal and Child Health \& Precision Medicine and UNESCO Chair on Adolescent Health Care, \\ National and Kapodistrian University of Athens, Aghia Sophia Children's Hospital, Athens, Greece \\ ${ }^{3}$ Laboratory of Genetics, Department of Biotechnology, School of Applied Biology and Biotechnology, Agricultural University of \\ Athens, Athens, Greece \\ ${ }^{4}$ Lab of Molecular Endocrinology, Center of Clinical, Experimental Surgery and Translational Research, Biomedical Research \\ Foundation of the Academy of Athens, Athens, Greece \\ Competing interests: ML none; PP none; FB none; DV none; GPC none; CD none
}

\section{Abstract}

A growing part of the literature has focused on depression, anxiety, distress and somatisation. Identifying their prevalence and populations at risk is essential to form relevant interventions. The aim of this study was to examine the prevalence and associated factors of distress, depression, anxiety, and somatisation in a community adult sample in Greece. Participants were recruited from two Greek cities; Giannitsa in the northern area and Athens in the southern area of the country, and completed sociodemographic assessments, as well as the 4-Dimensional Symptom Questionnaire (4-DSQ), a self-reported instrument assessing depression, anxiety, distress, and somatisation.

A total of 2,425 adults, females $(60.1 \%)$ and males (39.9\%), 18 to 84 years of age (mean age \pm SD, $46.98 \pm 9.57$ years) participated in the study. Mental health symptoms were reported by $10.8 \%$ for depression, $12 \%$ for anxiety, $13 \%$ for distress and 5.3\% for somatisation. Females scored higher than males in anxiety, distress, and somatisation ( $p=0.000$ in all cases), while there were no significant sex differences in depression $(p=0.593)$. Statistically significant associations were found between age and depression, anxiety and distress ( $\mathrm{p}=0.000$ in all cases), since those between 18-34 years of age had higher scores than the older age groups in all variables. Higher scores of depression, anxiety and distress were reported by students and unemployed participants ( $\mathrm{p}=0.000$ in all cases) than participants with other occupations.

This study mapped several sociodemographic groups with worse mental health. Studies in representative population samples are needed to guide public health interventions to improve the well-being of high-risk populations.

\section{Introduction}

According to the Global Burden of Disease Study, the prevalence of mental health disorders, such as depressive and anxiety disorders, has increased during the previous decades (Global Burden of Disease Study 2013 Collaborators, 2015). A wide range of changes in the way of living, which were intensified after the middle of the 20th century, such as urbanization, consumerism and secularization, are held responsible for the increased prevalence of these disorders (Hidaka, 2012).
Apart from clinically significant disorders, a major part of the research has focused on the impact of stress, which is causally related to the onset of several psychiatric disorders (Hammen, 2005; Pittenger and Duman, 2008). In addition, stress is related to various somatic disorders, such as coronary heart disease, breast cancer, multiple sclerosis, and diabetes type II (Antonova et al., 2011; Kelly and Ismail, 2015; Lin et al., 2013; Lloyd et al., 2005; McKay et al., 2017; Wirtz and von Känel, 2017). Hence,

\section{Article history}

Received: 27 November 2020

Accepted: 01 December 2020

Published: 08 October 2021

(c) 2021 Louvardi et al.; the authors have retained copyright and granted the Journal right of first publication; the work has been simultaneously released under a Creative Commons Attribution Licence, which allows others to share the work, while acknowledging the original authorship and initial publication in this Journal. The full licence notice is available at http://journal.embnet.org. 
stress should be considered as a major threat for public health.

Due to the aforementioned aggravating effects, it is of most importance to form a mechanism explaining the pathway from stress to chronic morbidity. As supported by several prominent professors in stress research, this effect can be explained by the negative impact of stress on the cardiovascular, gastrointestinal, muscular, immune and pulmonary function (Chrousos and Gold, 1992; McEwen, 1998). Somatisation refers to the process in which stress is experienced at a somatic level, affecting the homeostasis of such systems (Dantzer, 1995). As supported by Ford (1997), impaired capacity to communicate psychological experiences related to stress leads to somatisation.

Despite the fact that stress is experienced by literally everyone, some people are predisposed for increased stress levels, based on their sociodemographic profile. For example, the unemployed are a group experiencing high stress levels (Frasquilho et al., 2016). Yet, the impact of such factors is influenced by cultural parameters, highlighting the need to investigate such effects on different contexts (Marsh and Alvaro, 1990). Indeed, the heterogeneity of cultural norms indicates the necessity to study the mental health phenomena in divergent cultural contexts, to investigate if the recorded effects are common across the different contexts or not (Robson, 2002).

Based on the aforementioned evidence, it is of most importance to map high-risk populations for stress, anxiety, depression and somatisation, to provide a target for public health policies. The aim of this study was to examine the prevalence and associated factors of distress, depression, anxiety and somatisation in a community adult sample in Greece.

\section{Materials, Methodologies Techniques}

\section{Study design}

The design of the study was cross-sectional. Recruitment to the study was carried out in two different cities, in Athens, the capital city of Greece (664,046 inhabitants) and in Giannitsa, a city in northern Greece $(29,789$ inhabitants). The recruitment process began on 6 December 2018 and ended on 16 May 2019.

\section{Participants}

Study participants were adults, able to communicate verbally and in writing in Greek.

\section{Measurements}

\section{Sociodemographic data: Participants'} sociodemographic data included age (years), sex (male / female), family status (unmarried living alone/ unmarried living with a partner/ married/ widowed/ divorced), number of children, educational level
(Primary / Gymnasium / Lyceum / Tertiary / MSc / PhD), smoking status (current smoker / occasional smoker / non-smoker), and occupational status (unemployed / student / private sector worker / public sector worker / freelancer or businessman-woman / pensioner / house worker).

The 4-Dimensional Symptom Questionnaire: The 4-Dimensional Symptom Questionnaire (4-DSQ) is a self-reported instrument, including 50 items scored on a five Likert-type scale (zero=no to four=very much or always). This instrument includes four different subscales, measuring distress, depression, anxiety and somatisation (Terluin et al., 2006). The 4-DSQ has been validated in Greek (Tsourela et al., 2013). The range of a level was 0.90 for depression, 0.89 for anxiety, 0.92 for distress and 0.87 for somatisation.

\section{Procedures}

Prior to the beginning of the study, approval was obtained by the ethics committee of the Medical School of the National and Kapodistrian University of Athens. The study was in line with the Declaration of Helsinki. The recruitment process was carried out by a health visitor (ML) in Universities, public services, private companies and public spaces. A total of 3,000 participants were invited to participate and were informed about the purpose of the study, in face-to-face meetings. Those agreeing to participate provided informed consent and completed the assessments instantly or returned them on another day, based on relevant communication. The data collection was anonymous and confidential. The assessments were returned by 2,555 participants (response rate 85.17\%) and 2,425 completed questionnaires were further analysed. The average response time was approximately ten minutes.

\section{Statistical analysis}

The statistical analysis was carried out with the SPSS vol. 25 statistical software for Windows (Chicago Inc.). At first, descriptive statistics were applied to calculate the sociodemographic characteristics of the study sample. Descriptive statistics were also used to calculate the prevalence of elevated depression, anxiety, distress and somatisation levels, based on the cut-offs suggested by the developers of the 4-DSQ instrument (Terluin et al., 2006). Subsequently, inductive statistics were applied to search for relationships between the sociodemographic data of the study and the participants' score on the 4-DSQ. The independent samples T-Test was used when the sociodemographic variables were binary, and ANOVA when the sociodemographic variables had more than two values. Bonferroni post-hoc test and Mean Difference (M.D.) calculation followed the ANOVA analysis, in case of statistical significance. The level of significance was set at 0.05 for all the analyses. 
Table 1. Sociodemographic characteristics of the study participants.

\begin{tabular}{|c|c|}
\hline Characteristic & Absolute value (\%) \\
\hline \multicolumn{2}{|l|}{ Sex } \\
\hline Female & $1.458(60.1 \%)$ \\
\hline Male & 967 (39.9\%) \\
\hline \multicolumn{2}{|l|}{ Age } \\
\hline $18-34$ & $1.268(52.3 \%)$ \\
\hline $35-49$ & $754(31.3 \%)$ \\
\hline $50-64$ & $369(15.2 \%)$ \\
\hline 65 or more & $34(1.4 \%)$ \\
\hline \multicolumn{2}{|l|}{ Area of Residence } \\
\hline Athens & $1.791(73.9 \%)$ \\
\hline Giannitsa & $634(26.1 \%)$ \\
\hline \multicolumn{2}{|l|}{ Family status } \\
\hline Married & $834(34.4 \%)$ \\
\hline Unmarried, living alone & $1.022(42.1 \%)$ \\
\hline Unmarried, living with a partner & $417(17.2 \%)$ \\
\hline Widowed or divorced & $151(6.2 \%)$ \\
\hline \multicolumn{2}{|l|}{ Number of children } \\
\hline None & $1.584(65.3 \%)$ \\
\hline One & $385(15.9 \%)$ \\
\hline Two & $374(15.4 \%)$ \\
\hline Three or more & $82(3.4 \%)$ \\
\hline \multicolumn{2}{|l|}{ Educational status } \\
\hline Primary & $11(0.5 \%)$ \\
\hline Gymnasium & $18(1.6 \%)$ \\
\hline Lyceum & $661(27.3 \%)$ \\
\hline Vocational training & $300(12.4 \%)$ \\
\hline Tertiary & $1.033(42.6 \%)$ \\
\hline MSc & $343(14.1 \%)$ \\
\hline $\mathrm{PhD}$ & $39(1.6 \%)$ \\
\hline \multicolumn{2}{|l|}{ Occupational status } \\
\hline Private sector worker & $801(33 \%)$ \\
\hline Freelancer/businessman & $560(23.1 \%)$ \\
\hline Public sector worker & $474(19.5 \%)$ \\
\hline Student & $396(16.3 \%)$ \\
\hline Unemployed & $138(5.7 \%)$ \\
\hline Pensioner & $38(1.6 \%)$ \\
\hline Houseworker & $18(0.7 \%)$ \\
\hline \multicolumn{2}{|l|}{ Smoking status } \\
\hline Non-smoker & $1.387(57.2 \%)$ \\
\hline Current smoker & $741(30.6 \%)$ \\
\hline Occasional smoker & $297(12.2 \%)$ \\
\hline
\end{tabular}

\section{Results}

The descriptive data of the study sample are presented in Table 1.

Most participants were females (60.1\%), between 18-34 years of age (52.3\%), living in Athens (73.9\%), not having children (65.3\%). Concerning family status, the majority were unmarried, living alone (42.1\%), many
Table 2. Prevalence of levels depression, anxiety, distress and somatisation, according to the 4-DSQ.

\begin{tabular}{llll}
\hline \multicolumn{4}{c}{ Number of Participants (\%) } \\
\hline & Normal or mild & Moderate & Severe \\
\hline Depression & $1,803(74.4 \%)$ & $358(14.8 \%)$ & $262(10.8 \%)$ \\
\hline Anxiety & $1,582(65.3 \%)$ & $549(22.7 \%)$ & $290(12.0 \%)$ \\
\hline Distress & $1,381(57.1 \%)$ & $725(30.0 \%)$ & $314(13.0 \%)$ \\
\hline Somatisation & $1,713(70.8 \%)$ & $577(23.9 \%)$ & $128(5.3 \%)$
\end{tabular}

Table 3. Prevalence of levels depression, anxiety, distress and somatisation, by sex.

\begin{tabular}{lllll}
\hline \multicolumn{4}{c}{ Number of Participants (\%) } \\
\hline & \multicolumn{2}{c}{ Males } & \multicolumn{2}{c}{ Females } \\
\hline & $\begin{array}{l}\text { Normal, } \\
\text { mild or } \\
\text { moderate }\end{array}$ & Severe & $\begin{array}{l}\text { Normal, } \\
\text { mild or } \\
\text { moderate }\end{array}$ & Severe \\
\hline Depression & $883(91.4 \%)$ & $83(8.6 \%)$ & $1,324(90.9 \%)$ & $133(9.1 \%)$ \\
\hline Anxiety & $904(93.8 \%)$ & $60(6.2 \%)$ & $1,322(90.7 \%)$ & $135(9.3 \%)$ \\
\hline Distress & $877(91.1 \%)$ & $86(8.9 \%)$ & $1,229(84.4 \%)$ & $228(15.6 \%)$ \\
\hline Somatisation & $946(98.0 \%)$ & $19(2.0 \%)$ & $1,368(94.2 \%)$ & $85(5.8 \%)$ \\
\hline Total & \multicolumn{2}{c}{$967(100 \%)$} & \multicolumn{2}{c}{$1.458(100 \%)$}
\end{tabular}

were married (34.4\%), fewer were unmarried living with a partner $(17.2 \%)$, while the minority were widowed or divorced (6.2\%). As for the educational status, $42.6 \%$ were of tertiary education, while $27.3 \%$ were lyceum graduates. Regarding their occupational status, 33\% were private sector workers, $23.1 \%$ freelancers, $19.5 \%$ public sector workers and $16.3 \%$ were students. Finally, $57.2 \%$ were non-smokers, $30.6 \%$ were smokers and $12.2 \%$ were occasional smokers.

The prevalence of depression, anxiety, distress and somatisation in the study sample is presented at Table 2. Most participants had normal or mild levels of depression (74.4\%), anxiety (65.3\%), distress (57.1\%) and somatisation $(70.8 \%)$.

The prevalence of severely elevated levels of depression, anxiety, distress and somatisation by participants' sex is presented in Table 3. Females had higher scores than males in all sub-scales of 4-DSQ.

As indicated in Table 4, statistically significant associations were found between family status, educational status and occupational status in all subscales of the 4-DSQ. Concerning the age and number of the children, statistically significant associations were found in all sub-scales except for the somatisation subscale. Concerning participants' sex and smoking status, statistically significant associations were found in all sub-scales except the depression subscale. More specifically, males had lower scores than females $(p=0.000)$. As for the area of residence, no association was found with the depression, anxiety, distress or somatisation levels. 
Table 4. Associations of participants' sociodemographic variables and the 4-DSQ sub-scales.

\begin{tabular}{|c|c|c|c|c|c|c|c|c|}
\hline & \multicolumn{2}{|c|}{ Distress sub-scale } & \multicolumn{2}{|c|}{ Anxiety sub-scale } & \multicolumn{2}{|c|}{ Depression sub-scale } & \multicolumn{2}{|c|}{ Somatisation sub-scale } \\
\hline & $\begin{array}{l}\text { Mean value } \\
\text { (S.D) }\end{array}$ & $\mathbf{P}$ & $\begin{array}{l}\text { Mean value } \\
\text { (S.D) }\end{array}$ & $\mathbf{P}$ & $\begin{array}{l}\text { Mean value } \\
\text { (S.D) }\end{array}$ & $\mathbf{P}$ & $\begin{array}{l}\text { Mean value } \\
\text { (S.D) }\end{array}$ & $\mathbf{P}$ \\
\hline Sex & & 0.000 & & 0.000 & & 0.593 & & 0.000 \\
\hline Male & $8.52(7.22)$ & & $2.34(3.84)$ & & $1.34(2.64)$ & & $5.56(5.22)$ & \\
\hline Female & $10.79(7.99)$ & & $3.23(4.31)$ & & $1.40(2.67)$ & & $8.65(6.28)$ & \\
\hline Age & & 0.000 & & 0.000 & & 0.009 & & 0.325 \\
\hline $18-34$ & $10.92(7.89)$ & & $3.42(4.36)$ & & $1.55(2.78)$ & & $7.65(6.04)$ & \\
\hline $35-49$ & $9.05(7.52)$ & & $2.38(3.86)$ & & $1.18(2.48)$ & & $7.24(5.99)$ & \\
\hline $50-64$ & $8.20(7.40)$ & & $2.02(3.72)$ & & $1.18(2.54)$ & & $7.17(6.35)$ & \\
\hline 65 or more & $8.14(7.07)$ & & $2.94(4.53)$ & & $1.12(3.05)$ & & $6.69(0.12)$ & \\
\hline Area of residence & & 0.178 & & 0.604 & & 0.602 & & 0.336 \\
\hline Athens & $10.01(7.82)$ & & $2.85(4.18)$ & & $1.39(2.72)$ & & $7.36(5.94)$ & \\
\hline Giannitsa & $9.53(7.63)$ & & $2.95(4.10)$ & & $1.33(2.48)$ & & $7.63(6.40)$ & \\
\hline Family status & & 0.000 & & 0.000 & & 0.000 & & 0.005 \\
\hline Married & $8.34(7.33)$ & & $2.12(3.57)$ & & $1.05(2.35)$ & & $7.15(6.04)$ & \\
\hline Unmarried, living with a partner & $10.84(8.27)$ & & $3.13(4.16)$ & & $1.54(2.84)$ & & $8.22(6.09)$ & \\
\hline Unmarried, living alone & $10.72(7.76$ & & $3.37(4.44)$ & & $1.57(2.79)$ & & $7.22(5.95)$ & \\
\hline Widowed or divorced & $10.12(7.52)$ & & $3.01(4.53)$ & & $1.45(2.77)$ & & $8.28(6.71)$ & \\
\hline Number of children & & 0.000 & & 0.000 & & 0.001 & & 0.955 \\
\hline None & $10.59(7.86)$ & & $3.20(4.30)$ & & $1.51(2.75)$ & & $7.43(5.94)$ & \\
\hline One & $8.66(7.23)$ & & $2.39(3.90)$ & & $1.01(2.29)$ & & $7.57(6.26)$ & \\
\hline Two & $8.16(7.19)$ & & $2.05(3.44)$ & & $1.10(2.51)$ & & $7.33(6.26)$ & \\
\hline Three or more & $9.90(9.08)$ & & $2.74(4.64)$ & & $1.80(3.09)$ & & $7.32(6.74)$ & \\
\hline Educational status & & 0.010 & & 0.000 & & 0.000 & & 0.000 \\
\hline Primary & $7.63(11.02)$ & & $3.18(6.63)$ & & $1.54(3.38)$ & & $8.90(10.24)$ & \\
\hline Gymnasium & $11.26(8.11)$ & & $4.10(5.42)$ & & $2.44(3.64)$ & & $8.28(6.78)$ & \\
\hline Lyceum & $10.59(8.13)$ & & $3.38(4.54)$ & & $1.75(3.02)$ & & $7.57(6.44)$ & \\
\hline Vocational training & $9.52(7.66)$ & & $2.96(4.18)$ & & $1.12(2.22)$ & & $8.35(6.19)$ & \\
\hline Tertiary & $9.81(7.65)$ & & $2.72(3.93)$ & & $1.26(2.54)$ & & $7.40(5.88)$ & \\
\hline MSc & $9.34(7.39)$ & & $2.29(3.78)$ & & $1.17(2.52)$ & & $6.72(5.52)$ & \\
\hline $\mathrm{PhD}$ & $6.63(6.66)$ & & $1.58(2.63)$ & & $0.53(1.46)$ & & $4.02(4.18)$ & \\
\hline Occupational status & & 0.000 & & 0.000 & & 0.000 & & 0.000 \\
\hline Unemployed & $12.12(8.51)$ & & $4.25(5.06)$ & & $2.22(3.54)$ & & $8.10(6.44)$ & \\
\hline Student & $11.98(7.97)$ & & $4.17(4.77)$ & & $1.82(3.03)$ & & $7.82(6.14)$ & \\
\hline Public sector worker & $8.63(7.43)$ & & $2.26(3.63)$ & & $1.04(2.32)$ & & $6.85(6.04)$ & \\
\hline Private sector worker & $9.78(7.85)$ & & $2.85(4.16)$ & & $1.34(2.59)$ & & $8.10(6.35)$ & \\
\hline Freelancer/businessman & $9.30(7.22)$ & & $2.23(3.56)$ & & $1.20(2.42)$ & & $6.58(5.34)$ & \\
\hline Pensioner & $7.34(6.09)$ & & $1.89(2.20)$ & & $0.94(2.25)$ & & $6.64(4.96)$ & \\
\hline Houseworker & $8.05(9.82)$ & & $3.22(6.19)$ & & $1.72(3.30)$ & & $8.00(6.07)$ & \\
\hline Smoking status & & 0.001 & & 0.031 & & 0.080 & & 0.000 \\
\hline Current smoker & $10.51(8.20)$ & & $3.07(4.34)$ & & $1.55(2.84)$ & & $8.25(6.51)$ & \\
\hline Non-smoker & $9.37(7.50)$ & & $2.69(4.04)$ & & $1.28(2.58)$ & & $6.97(5.82)$ & \\
\hline Occasional smoker & $10.71(7.73)$ & & $3.25(4.19)$ & & $1.38(2.58)$ & & $7.54(5.86)$ & \\
\hline
\end{tabular}

Post-hoc analysis demonstrated several differences between groups. Specifically, participants aged 1834 years showed higher levels of distress (M.D. 1.86, $\mathrm{p}=0.000$ ), anxiety (M.D. 1.04, $\mathrm{p}=0.000$ ) and depression (M.D. 0.37, $\mathrm{p}=0.028$ ) than the $35-49$ age group. Also, participants aged 18-34 years reported higher levels of distress (M.D. 2.72, $\mathrm{p}=0.000$ ) and anxiety (M.D. 1.40, $\mathrm{p}=0.000$ ) than the 50-64 age group.

With regards to family status, statistically significant differences were found between married and unmarried living with a partner participants; the latter group reported higher levels of distress (M.D. $-2.50, \mathrm{p}=0.000$ ), anxiety (M.D. $-1.00, \mathrm{p}=0.001$ ), depression (M.D. -0.488 , 
$\mathrm{p}=0.025)$, and somatisation (M.D. 1.072, $\mathrm{p}=0.019$ ) Nevertheless, married participants demonstrated lower levels of distress (M.D. -2.37, $\mathrm{p}=0.000$ ), anxiety (M.D. 1.25, $\mathrm{p}=0.000$ ), depression (M.D. -0.517, $\mathrm{p}=0.001$ ), and somatisation (M.D. 1.003, $\mathrm{p}=0.027$ ) than those living alone.

With respect to children, participants who did not have children reported higher scores in distress (M.D. 1.92, $\mathrm{p}=0.000$ ), anxiety (M.D. 0.80, $\mathrm{p}=0.008$ ), and depression (M.D. 0.498, $\mathrm{p}=0.013$ ) than those with one child, as well as higher levels of distress (M.D. 2.43, $\mathrm{p}=0.000$ ), and anxiety (M.D. $1.15, \mathrm{p}=0.000$ ) than those with two children.

With reference to occupational status, the unemployed participants reported higher levels of distress (M.D. 3.55, p=0.001), anxiety (M.D. 1.99, $\mathrm{p}=0.000$ ), and depression (M.D. 1.17, $\mathrm{p}=0.002$ ) than the public sector workers, as well as higher levels of distress (M.D. 2.88, p=0.002), anxiety (M.D. 2.01, $\mathrm{p}=0.000$ ), and depression (M.D. 1.02, $\mathrm{p}=0.012$ ) than the freelancers. Furthermore, the unemployed participants reported higher levels of distress (M.D. 2.40, $\mathrm{p}=0.015$ ), anxiety (M.D. 1.39, $\mathrm{p}=0.034$ ), and depression (M.D. 0.877, $\mathrm{p}=0.045)$ than the private sector workers. Also, students reported higher levels of distress (M.D. 3.35, $\mathrm{p}=0.000$ ), and depression (M.D. 0.776, $\mathrm{p}=0.005$ ) than public sector workers, higher levels of distress (M.D. 2.19, $\mathrm{p}=0.001$ ) than private sector workers, and higher levels of distress (M.D. 2.68, $\mathrm{p}=0.000$ ), anxiety (M.D. 1.94, $\mathrm{p}=0.000$ ), and depression (M.D. 0.621, $\mathrm{p}=0.048$ ) than the freelancers. Moreover, private sector workers reported higher levels of somatisation than public sector workers (M.D. 1.24, $\mathrm{p}=0.049)$ and freelancers (M.D. 1.51, $\mathrm{p}=0.002$ ).

Likewise, statistically significant differences were found between smokers and non-smokers with the latter group reporting lower scores in distress (M.D. 1.13, $\mathrm{p}=0.006$ ) and somatisation (M.D. 1.28, $\mathrm{p}=0.000$ ), as well as between occasional smokers and non-smokers, with the latter group reporting lower scores in distress (M.D. 1.33, $\mathrm{p}=0.027$ ).

With regards to the educational status, $\mathrm{PhD}$ students reported lower levels of distress (M.D.-3.966, $\mathrm{p}=0.046$ ) than the Lyceum graduates. As for anxiety, statistically significant differences were noted between Lyceum and MSc participants, (M.D. 1.094, p=0.002), as well as between Lyceum and tertiary education participants (M.D. 0.663, $\mathrm{p}=0.028$ ). As for depression, statistically significant differences were found between Lyceum and tertiary educational level (M.D. 0.490, $\mathrm{p}=0.033$ ) participants, Lyceum and MSc participants (M.D. 0.584, $\mathrm{p}=0.020$ ), Lyceum and vocational training (M.D. 0.632, $\mathrm{p}=0.014$ ) participants. Differences were also noted between PhD participants and other educational groups; more specifically $\mathrm{PhD}$ participants, demonstrated lower distress levels (M.D. -1.908, p=0.034) than Gymnasium participants, as well as lower levels of somatisation than tertiary education participants (M.D. -3.375, $\mathrm{p}=0.013$ ), Lyceum graduates (M.D. $-3.547, \mathrm{p}=0.008$ ), vocational training graduates (M.D. $-4.331, \mathrm{p}=0.001$ ) and Gymnasium graduates (M.D. -4.263, $\mathrm{p}=0.042$ ).

\section{Discussion}

This study investigated the prevalence of depression, anxiety, distress and somatisation in an adult community sample in Greece, as well as associated factors. In the sample studied, $10.8 \%$ of the participants had severe depressive symptoms, while anxiety, distress and somatisation were reported by $12 \%, 13 \%$ and $5.3 \%$ of the participants, respectively. Higher prevalence was noted for moderate distress (43\%) compared to the other studied parameters $(24.8 \%-34.7 \%)$. As for the associated factors, there were significant sex differences in anxiety, distress, and somatisation, since females had higher scores, while there were no significant differences for depression. Concerning age, higher scores of depression, anxiety, distress and somatisation were found for younger participants, especially for those aged 18-34 years old. Higher scores of depression, anxiety and distress were found for students and the unemployed, whereas private sector workers had higher scores of somatisation compared to public sector workers and freelancers. Also, participants who were married and those with children had lower scores of distress, anxiety, depression and somatisation, while the unmarried living with a partner or not and those with no children had higher scores in all subscales. Smokers experienced worse mental health and somatisation compared to the others. Finally, participants with a PhD had lower scores in all subscales. At last, there are no statistically significant differences in the parameters studied between participants residing in the two cities in the northern and southern areas of the country.

The prevalence of severe depressive symptoms $(10.8 \%)$ in this study is similar to that reported in other countries. For example, Johansson et al. (2013) found that $10.8 \%$ of the Swedish general population had clinically significant depressive symptoms, while Doğan et al. (2011) found that $12.8 \%$ of the general population in Turkey had such symptoms. In addition, Johansson et al. (2013) found that $14.7 \%$ of the responders had severe anxiety, which is slightly higher compared to the $12 \%$ found in the present study. As for somatisation, the reported $5.3 \%$ of severe symptoms in the present study is quite similar to the $5 \%$ found by Lee et al. (2015), who investigated somatisation in the general population in Hong Kong and to the $6.3 \%$ of somatoform disorders found by Wittchen et al. (2011) across the EU countries. Thus, it seems that the prevalence of depression, anxiety and somatisation is quite similar across different countries and is not strongly affected by cultural norms.

Most of the study findings concerning the associated factors are in line with previous research. For example, the findings of the present study support that those living in a family and having children have better mental health and lower somatisation compared to the others. This finding confirms the already known theories about the 
protective effect of social ties on human health (Moore and Kawachi, 2017). However, a finding that is not in line with other studies is the absence of statistically significant differences between males and females in depression, since according to the World Health Organization (2017) males experience lower depression levels.

Another finding that is in line with the previous literature concerns the association of smoking status with mental health and somatisation. As supported by West (2017), this association is quite common in the literature, although there is no commonly accepted mechanism of why smokers experience worse mental health. According to his point of view, this effect could be explained by the higher levels of life satisfaction of the non-smokers. An alternative explanation could be that smokers are aware of the potentially harmful effect of smoking, as well as that they feel guilt for placing their health under threat. These findings are in line with research in patients affected by smoking-related diseases, especially lung cancer (Weiss et al., 2017). In addition, it could be supported that smokers have higher trait anxiety levels, since smoking is considered as a maladaptive way to set anxiety under control (Wiggert et al., 2016).

As for the effect of educational status on the components of mental and physical well-being, the findings of the present study contradict previous research supporting that high education in general leads to better mental and physical health outcomes (Berkman et al., 2014), since only those with extremely high educational level were found to be protected. It could be supported that in the Greek market there is no strong association between education and work positions, since many people do not work on their field of expertise, a problematic condition present in Greece even before the economic crisis period (Liagouras et al., 2003; Livanos, 2010). Hence, the protective effect might exist only for those with extremely high education, which might work on their field of expertise and have better career prospects.

In general, the results of the present study have to be examined in parallel with the effects of the recent economic crisis on Greece. The unemployment and insecurity for younger people (Frangos et al., 2012) could be responsible for their worse mental health compared to older participants. Similarly, the worse mental health of students could be explained by such an effect. Yet, this might not account only for Greece, since a wide range of studies across different populations confirms that students have high rates of mental health problems (AlDaghri et al., 2014; Auerbach et al., 2016; Bayram and Bigel, 2008).

Finally, the higher levels of somatisation of the private sector workers compared to public sector workers and freelancers, is a quite interesting finding with no obvious explanation. It could be supported that public sector workers experience higher levels of security in their employment status (since according to Greek laws they can't be fired), while freelancers experience a higher degree of freedom and opportunities for further financial growth. However, private sector workers do not experience any of those benefits. As supported by Ford (1997), somatisation is experienced because of inability to express the psychological burden, a justified and forced "inability" in a workplace environment. Thus, it might be easier for private sector workers to somatise their emotional burden.

A few limitations have to be reported concerning this study. Firstly, some sociodemographic data such as participants' body mass index (BMI), the presence of chronic disease and the income status were not assessed. The study followed a convenient sampling approach, nevertheless the sample size was quite large and was recruited from two different areas of the country (urban and rural). Although mental health was assessed with self-reported instruments with high psychometric properties, the use of interviews is considered as a more reliable way to study depression (Robson, 2002).

Based on the findings and the limitations of the present study, some suggestions could be made for future research. As quantitative studies are not extremely reliable to shed light on the mechanism of the studied phenomena (Robson, 2002), the use of qualitative methods (e.g. interviews) could be more reasonable to investigate the potential mechanism for these effects (e.g. the worse mental health of smokers and young people), to provide in-depth explorations, and to form relevant theories (Babbie, 2013).

As for practical implications, the high percentage of participants experiencing moderate or severe distress (42.9\%) indicates the need to develop stress-management interventions in the community. Finally, this study highlighted specific populations, such as students and those aged 18-34 years, who experience poor mental health and high somatisation. For that reason, public health policy makers should focus on the development of interventions aiming at the improvement of mental and physical well-being especially for those age groups.

\footnotetext{
Key Points

Approximately one third of an adult community sample in Greece suffered from moderate to severe mental health symptoms.

Marriage, having children, non-smoking and higher educational status had protective effect on mental health.

- Students, unemployed and private sector workers had higher levels of depressive, anxiety, distress and somatisation symptoms.

Youth's mental health was worse than the elder's.

- Sex differences were noted in all aspects of mental health symptoms except for depression.
}

\section{Acknowledgments}

We would like to thank all the study participants for their valuable time.

\section{References}

1. Al-Daghri N, Al-Othman A, Albanyan A, Al-Attas OS, Alokail MS et al. (2014) Perceived stress scores among Saudi students entering universities: A prospective study during the first year of university life. International journal of environmental research 
and public health, 11(4), 3972-3981. http://dx.doi.org/10.3390/ ijerph110403972

2. Antonova L, Aronson K and Mueller CR (2011) Stress and breast cancer: from epidemiology to molecular biology. Breast Cancer Research, 13(2),208. http://dx.doi.org/10.1186/bcr2836

3. Auerbach RP, Alonso J, Axinn WG, Cuijpers P, Ebert DD et al. (2016) Mental disorders among college students in the World Health Organization world mental health surveys. Psychological medicine, 46(14),2955-2970. http://dx.doi.org/10.1017/ S0033291716001665

4. Babbie ER (2013) The basics of social research. Cengage Learning

5. Bayram N and Bilgel N (2008) The prevalence and sociodemographic correlations of depression, anxiety and stress among a group of university students. Social psychiatry and psychiatric epidemiology, 43(8), 667-672. http://dx.doi.org/10.1007/s00127008-0345-x

6. Berkman LF, Kawachi I, Glymour MM (2014) Social epidemiology. Oxford University Press.

7. Chrousos GP and Gold PW (1992) The concepts of stress and stress system disorders: overview of physical and behavioral homeostasis. Jama, 267(9), 1244-1252. http://dx.doi.org/10.1001/ jama.1992.03480090092034

8. Dantzer R (1995) Stress theories and the somatization process L'Encephale, 21, 3-9.

9. Doğan Y, Onat A, Kaya H, Ayhan E, Can G (2011) Depressive symptoms in a general population: associations with obesity, inflammation, and blood pressure. Cardiology research and practice, 2011. http://dx.doi.org/10.4061/2011/740957.

10. Ford CV (1997) Somatic symptoms, somatization, and traumatic stress: An overview. Nordic Journal of Psychiatry, 51(1), 5-13. http://dx.doi.org/10.3109/08039489709109078

11. Frangos C, Frangos C, Sotiropoulos I, Orfanos V, Toudas $\mathrm{K}$ et al. (2012) The effects of the Greek economic crisis on eating habits and psychological attitudes of young people: A sample survey among Greek university students. In Proceedings of the World Congress of Engineering (Vol. 1).

12. Frasquilho D, de Matos MG, Marques A, Gaspar,, T,., Caldasde-Almeida JM (2016) Distress and unemployment: the related economic and noneconomic factors in a sample of unemployed adults. International journal of public health, 61(7), 821-828. http://dx.doi.org/10.1007/s00038-016-0806-z

13. Global Burden of Disease Study 2013 Collaborators (2015) Global, re-gional, and national incidence, prevalence, and years lived with disability for 301 acute and chronic diseases and injuries in 188 countries, 1990-2013: A systematic analysis for the Global Burden of Disease Study 2013. Lancet: 386, 743-800

14. Hammen C (2005) Stress and depression. Annu. Rev. Clin Psychol., 1,293-319. http://dx.doi.org/10.1146/annurev. clinpsy.1.102803.143938

15. Hidaka BH (2012) Depression as a disease of modernity: explanations for increasing prevalence. Journal of affective disorders, 140(3), 205-214. http://dx.doi.org/10.1016/j. jad.2011.12.036

16. Johansson R, Carlbring P, Heedma, Paxling B, Andersson G (2013) Depression, anxiety and their comorbidity in the Swedish general population: point prevalence and the effect on healthrelated quality of life. PeerJ, 1, e98. http://dx.doi.org/10.7717] peerj.98

17. Kelly SJ and Ismail M (2015) Stress and type 2 diabetes: a review of how stress contributes to the development of type 2 diabetes. Annual review of public health, 36, 441-462. http://dx.doi org/10.1146/annurev-publhealth-031914-122921

18. Lee S, Leung CM, Kwok KP, Lam NK (2015) A community-based study of the relationship between somatic and psychological distress in Hong Kong. Transcultural psychiatry, 52(5), 594-615. http://dx.doi.org/10.1177/1363461515569756
19. Liagouras G, Protogerou A, Caloghirou Y (2003) Exploring mismatches between higher education and the labour market in Greece. European Journal of Education, 38(4), 413-426.

20. Lin Y, Wang C, Zhong Y, Huang X, Peng L et al. (2013) Striking life events associated with primary breast cancer susceptibility in women: a meta-analysis study. Journal of Experimental and Clinical Cancer Research, 32(1), 53.

21. Livanos I (2010) The relationship between higher education and labour market in Greece: the weakest link? Higher Education, 60(5), 473-489. http://dx.doi.org/10.1007/s10734-010-9310-1

22. Lloyd C, Smith J, Weinger K (2005) Stress and diabetes: a review of the links. Diabetes spectrum, 18(2):121-127. http://dx.doi. org/10.2337/diaspect.18.2.121

23. Marsh C and Alvaro JL (1990) A cross-cultural perspective on the social and psychological distress caused by unemployment: a comparison of Spain and the United Kingdom. European Sociological Review, 6(3):237-256. http://dx.doi.org/10.1093/ oxfordjournals.esr.a036564

24. McEwen BS (1998) Stress, adaptation, and disease: Allostasis and allostatic load. Annals of the New York academy of sciences, 840(1):33-44. http://dx.doi.org/10.1111/j.1749-6632.1998. tb09546.x

25. McKay KA, Jahanfar S, Duggan T, Tkachuk S, Tremlett H (2017) Factors associated with onset, relapses or progression in multiple sclerosis: a systematic review. Neurotoxicology, 61:189-212. http://dx.doi.org/10.1016/j.neuro.2016.03.020

26. Moore S and Kawachi I (2017) Twenty years of social capital and health research: a glossary. J Epidemiol Community Health, 71(5): 513-517. http://dx.doi.org/10.1136/jech-2016-208313

27. Pittenger $\mathrm{C}$ and Duman RS (2008) Stress, depression, and neuroplasticity: a convergence of mechanisms. Neuropsychopharmacology, 33(1):88.

28. Robson C (2002) Real World Research (2nded.). Oxford: Blackwell Publishing.

29. Terluin B, van Marwiik HW, Adèr HJ, de Vet HC, Penninx BW et al. (2006) The Four-Dimensional Symptom Questionnaire (4DSQ): a validation study of a multidimensional self-report questionnaire to assess distress, depression, anxiety and somatization. Bmc Psychiatry, 6(1):34.

30. Tsourela M, Mouza AM, Paschaloudis D (2013) Assessing Distress with the Four Dimensional Symptom Questionnaire (4DSQ). A Case Study Regarding the Private and Public Sector in Greece. Proceedings of the Eighth International Conference on "New Horizons in Industry, Business and Education",29-30 August 2013,Chania, Crete island, Greece, 341-345.

31. Weiss J, Yang H, Weiss S, Rigney M, Copeland A et al. (2017) Stigma, self-blame, and satisfaction with care among patients with lung cancer. Journal of psychosocial oncology, 35(2):166179. http://dx.doi.org/10.1080/07347332.2016.1228095

32. West R (2017) Tobacco smoking: Health impact, prevalence, correlates and interventions. Psychology and health, 32(8): 10181036. http://dx.doi.org/10.1080/08870446.2017.1325890

33. Wiggert N, Wilhelm FH, Nakajima M, al'Absi M (2016) Chronic smoking, trait anxiety, and the physiological response to stress. Substance use and misuse, 51(12):1619-1628. http://dx.doi.org/1 $0.1080 / 10826084.2016 .1191511$

34. Wirtz PH and von Känel R (2017) Psychological stress, inflammation, and coronary heart disease. Current cardiology reports, 19(11):111. htpp://dx.doi.org/. 10.1007/s11886-017. 0919-x

35. Wittchen H U, Jacobi F, Rehm J, Gustavsson, A, Svensson $\mathrm{M}$ et al. (2011) The size and burden of mental disorders and other disorders of the brain in Europe 2010. European neuropsychopharmacology, 21(9): 655-679. http://dx.doi. org/10.1016/j.euroneuro.2011.07.018

36. World Health Organization (2017) Depression and other common mental disorders: global health estimates (No. WHO/ MSD/MER/2017.2). World Health Organization. 